\title{
When Kids are the Last to Know: Embodied Tensions in Surprising Children with Family Vacations
}

Jenna M. Drenten

Loyola University Chicago, jdrenten@luc.edu

Follow this and additional works at: https://ecommons.luc.edu/business_facpubs

Part of the Business Commons

\section{Recommended Citation}

Drenten, Jenna M.. When Kids are the Last to Know: Embodied Tensions in Surprising Children with Family Vacations. Young Consumers, 19, 2: 199-217, 2018. Retrieved from Loyola eCommons, School of Business: Faculty Publications and Other Works, http://dx.doi.org/10.1108/YC-08-2017-00728

This Article is brought to you for free and open access by the Faculty Publications and Other Works by Department at Loyola eCommons. It has been accepted for inclusion in School of Business: Faculty Publications and Other Works by an authorized administrator of Loyola eCommons. For more information, please contact ecommons@luc.edu.

\section{(c) (1) $(9)$}

This work is licensed under a Creative Commons Attribution-Noncommercial-No Derivative Works 3.0 License. (c) Emerald Publishing Limited 2018 
Citation: Drenten, Jenna. "When kids are the last to know: embodied tensions in surprising children with family vacations." Young Consumers, vol. 19, no. 2, 2018, pp. 199-217.

\title{
When Kids are the Last to Know:
}

\section{Embodied Tensions in Surprising Children with Family Vacations}

\begin{abstract}
Purpose-Surprise family vacations have become increasingly prevalent in today's digitally mediated consumer culture. Drawing on a performance based view of tourism, this article explores the performance practices and embodied experiences by which young consumers are the recipients of last-minute surprise vacations.

Methodology — YouTube offers a space for examining surprise family vacations, as captured in real-time by consumers. The visual elements and verbal discourses of 139 surprise family vacation reveal videos were analyzed using a hermeneutical approach.

Findings - Findings suggest surprise family vacations are characterized by three performance practices in which embodied tensions arise between normative expectations and unanticipated experiences: executing the reveal (scripted act versus improvised act), announcing the destination (absolute ideal versus relative ideal), and reacting to the surprise (initial acceptance versus initial rejection).

Research implications - By exploring a phenomenon in which children's anticipation for a vacation is largely absent or limited, surprise family vacations reveal culturally idealized norms and performative practices in family tourism. Positioning a family vacation as an offering or
\end{abstract}


surprise for the children is distinct from previous research, which suggests family vacations are co-created. Children of all ages experience tourism-related stresses and anxieties.

Practical implications - The primary practical contribution for marketers lies in revealing how the material and performative practices of a family vacation begins even before a family enters its tourist destination. Service providers and retailers may provide offerings for families to support surprise family vacations, particularly in an increasingly digital culture. The study also reveals opportunities for parents to strategically discuss surprise vacations with their kids.

Originality/Value - This study captures the liminal moment in which a child's tourism journey begins. By utilizing YouTube as a resource for digital ethnography, researchers can better understand how families discuss, negotiate, and mediate tourism-oriented concepts, through their lived experiences.

KEYWORDS: family tourism, surprise family vacation, performance, anticipation, YouTube, family decision making 


\title{
When Kids are the Last to Know:
}

\section{Embodied Tensions in Surprising Children with Family Vacations}

\begin{abstract}
Anticipation is part of the joy of a family vacation. You tell the kids, you plan the trip, you talk about how much you're looking forward to it. But there's another way to travel: Plan the whole thing in secret, then spring it on the kids once you're in the car and on the road. These five tips are all but guaranteed to give you the gift of shrieks of joy the minute the kids discover they are going on a surprise vacation! (Topinka, 2015)
\end{abstract}

Social media is flooded with videos of crying, screaming, often perplexed children who have just been surprised with a family vacation. These feel-good, entertaining videos are commonplace today. With nearly 16 million views on YouTube, the most popular and famous 'vacation reveal' video is "Lily’s Disneyland Surprise....AGAIN!" (Hastings, 2013). The video features two young girls, Lily (age 8) and Chloe (age 2), in the backseat of their family car on the way to Lily's school one morning. Their father drives as their mother films the two girls from the passenger's seat. Lily laments about having to go to school, when suddenly-they pass her school. They pull over to the side of the road, and surprise: the girls' mom reveals they are skipping school and going on a three-day vacation to Disneyland. Lily cries tears of joy as her younger sister, Chloe, remains skeptical (see Figure 1). Lily cries tears of joy as her younger sister, Chloe, remains skeptical (www.youtube.com/watch?v=NGhuLkj14iI). Lily and Chloe's divergent reactions illustrate children's nuanced experiences as they unexpectedly and instantly become participants in family tourism.

Surprise family vacations are not a new phenomenon - they predate social media and online consumer culture; however, surprise vacation reveal videos have become a mainstay in today's socially mediated culture. A search on YouTube for "surprise trip for kids" yields nearly 
5 million video results. The trend is further reinforced in the marketplace through travel services like Pack Up + Go, which offers family-friendly weekend getaways to mystery destinations, and websites like Etsy and Pinterest, which promote products used to facilitate vacation reveals (e.g., printable scavenger hunt clues, customized surprise vacation puzzles).

Previous research suggests children can act as co-decision makers in the family vacation planning process (Gram, 2007); however, in the case of surprise family trips, children are the last to know. That is, children are not directly involved in pre-vacation consumption choices. Surprise family vacations are unique in that children are not co-decision makers; rather, they are positioned as both the impetus for and the recipients of the family trip. The rise in popularity of surprise vacation reveal videos offers an opportunity to explore the performance of and potential tradeoffs in surprising children with family vacations.

Drawing on a conceptual lens of performance, the goal of this research is to examine the practices by which surprise family vacations are enacted and how such experiences might give rise to embodied tensions. The study uses a unique qualitative approach of digital ethnography, in which 139 surprise vacation reveal videos were collected via YouTube and analyzed. Reveal videos document young consumers' experiences as their parents announce an unexpected trip. Thus, this study captures the liminal moment in which a child's tourism journey begins. In contributing to the literature on family consumption in tourism, findings suggest surprise family vacations are characterized by three performance practices in which embodied tensions arise between normative expectations and unanticipated experiences: executing the reveal (tension between scripted act versus improvised act), announcing the destination (tension between absolute ideal versus relative ideal), and reacting to the surprise (tension between initial acceptance versus initial rejection). Implications are offered for marketers to responsibly 
leverage surprise family vacation performance practices and for families to avoid embodied tensions. Methodological and future research opportunities are also presented.

\section{CONCEPTUAL FOUNDATION}

\section{Co-created Family Tourism and Surprise Family Vacations}

Cultural parenting practices have shifted toward a more collaborative, democratic, and child-centered style, which has permeated how families approach tourism decisions (Schänzel and Yeoman, 2015). Young consumers actively voice their tourism preferences and expect their opinions to be taken seriously. In turn, driven by a desire to create positive memories through experiential quality time, parents are motivated to meet their children's needs ( $\mathrm{Li}$, Wang, $\mathrm{Xu}$, and Mao, 2017). Families seek child-friendly destinations (e.g., zoos, Therkelsen and Lottrup, 2015), child-friendly amenities (e.g., swimming pools, theme parks, Thornton, Shaw, and Williams, 1997), and child-friendly activities (e.g., dress-up play, arts and crafts, Khoo-Lattimore, Prayag, and Cheah, 2015). Early family tourism research asserted that children merely conform to their parents' wishes (Foxman, Tansuhaj, and Ekstrom, 1989). However, children are increasingly recognized as co-creators, rather than passive participants in the family tourism experience (Therkelson, 2010; Thornton et al., 1997; Aleti Watne, Brennan, and Winchester, 2014). In surveying museum visitors, Wu, Holmes, and Tribe (2010) find parents include their children in tourism decisions through various strategies, including offering a range of options (e.g., Do you want to go to the park, to the library, or to the museum?), soliciting ideas from kids (e.g., What do you want to do today?), and taking a family vote. 
In contrast to a collaborative, co-creation perspective of tourism, surprise family vacations are unique because children are purposefully excluded from the trip planning process. Surprise family vacations are positioned as gifts for the children. When receiving tangible surprise gifts, children may feel disappointed by unwanted gifts but are socialized to control their emotions - because after all, they should be grateful (Kieras, et al., 2005). Similarly, the underlying assumption in surprise family vacations is that children will be thrilled by the surprise and eager to go on a vacation. But what happens when children, lacking the opportunity and/or ability to anticipate a pending vacation, react differently than expected? Research suggests family vacations can be particularly straining as parents and children may have conflicting desires (e.g., relaxation versus play; Gram, 2005), especially in families with young children (Backer and Schänzel, 2013). In studying how adolescents manage vacation-oriented conflict with their parents, Singh and Nayak (2014) assert teenage consumers are "no longer submissive to parental choices" and "want to [...] be a part of the planning process" (p. 89). Yet, a dearth of research examines children's lived experiences of vacation-related stresses or emergent conflict, in situ.

Surprise vacation reveal videos capture the moment in which such conflict may emergewhen a child suddenly discovers he or she will be going on vacation. In today's digitallymediated culture, the prevalence of surprise family vacation videos is exacerbated by parents' willingness to engage in 'sharenting,' or sharing the day-to-day details of their children's lives (Steinberg, 2016). Using performance theory as a metaphorical lens through which to examine surprise family vacation reveals, this study aims to explore families' practices and children's embodied experiences as they become tourists. 


\section{Performance Theory in Tourism}

Tourism is increasingly recognized as a performance-oriented process by which consumers co-create meaning, as their travel experiences intersect with their daily lives (Bærenholdt, et al., 2017; Coleman and Crang, 2002; Edensor, 2000). Drawing primarily on Goffman's (1959) dramaturgical framework, scholars have theorized tourism as a performance and explored the performativity involved in tourism related contexts, from hotel room attendants find dignity through performing their daily tasks (Kensbock, Jennings, Bailey, and Patiar, 2016) to how cruise ship passengers perform expectations of escapism (Kang, Manthiou, Kim, and Hyun, 2015). Goffman (1959) suggests all social life and social interactions take place on a metaphorical stage upon which people play strategic roles, deliver culturally scripted lines, and perform with an imagined audience in mind. Through their actions and discourses, both tourists and tourism service providers enact embodied practices and articulate shared meanings related to tourism. For instance, tourist photography is a type of performance as tourists take stylized selfies at museums to embed themselves in the focal attractions (e.g., interacting with the artwork) and capture unexpected versions of themselves (e.g., strange faces and poses; Dinhopl and Gretzel, 2016). Specifically, in the context of family tourism, family members hug or stand close to one another in photographs, thus performing societal expectations of closeness and intimacy among family members (Larsen, 2005).

In tourism studies, the notion of performance "is concerned with exploring in detail how tourists, as creative and expressive beings, plan their journeys, 'do' things, experience and exhibit, how they in part produce and circulate experiences" (Ek, et al., 2008, p. 126). Larsen and Urry (2011) identify several key characteristics of the performance perspective in tourism research. First, performance research emphasizes touristic experiences and enactments (i.e., what 
tourists do). The emphasis is placed heavily on embodied experience of being a tourist. In his ethnographic study of tourists on Halloween holiday in Transylvania, Romania, Light (2009) describes the embodied tourist experience of exploring the "Castle Dracula," a hotel inspired by Dracula. By roaming the hallways, climbing the multitude of staircases, and even spending a night in the hotel, "tourists were not simply encountering Transylvania - instead they were performing a Transylvania as they imagined it to be" (Light, 2009, p. 240). Second, tourists' social interactions are initially scripted and staged, based on societal norms and expectations, with adjustments made as the performance unfolds. Tourists adapt to changes in the script or setting, underscoring the fluid nature of the performance itself. Larsen and Urry (2011, p. 1113) theorize "performance as a form of playful ritualised behavior," which is "partly constrained and partly innovative." Third, tourist places are fluid and are inclusive of the daily tools and tasks that support tourist performances. For instance, a tourist may frequent a tanning salon in preparation for a tropical vacation. The tanning salon is then part of the tourism performance. Consumers do not become tourists only when they step foot onto an airplane or arrive at a museum. Rather, they perform tourism practices cyclically—before, during, and after each tourism-oriented event. Tourism is a malleable experience rather than a fixed destination. Tourist performances are created through anticipating future vacations and reflecting on past ones (Bærenholdt et al., 2017).

In line with previous performance theory research in tourism, the focus of this study remains on the lived experience of being, or in this case, of instantly becoming a tourist - the liminal moment in which a child discovers he or she will be going on a vacation. Thus, this research explores the following questions: 1) what are the performance practices by which 
surprise family vacations unfold, and 2) how might children's embodied experiences of being surprised with family vacations give rise to tensions?

\section{METHODOLOGY}

YouTube is a rich source of narrative and digital ethnographic data, which offers a unique opportunity for interpretive consumer research (Chenail, 2011; Masten and Plowman, 2003; Pace, 2008). Given its ability to capture real-world lived experiences, YouTube is an ideal setting for exploring families' experiences with surprise vacation reveals. Unlike other qualitative methods (e.g., interviews, diaries), YouTube surprise vacation reveal videos capture families' experiences in the moment and, typically, unedited. Such consumer generated visual images are valuable as they reflect "staged spontaneity, in the moment, 'authentic' record[s] of consumer experience" (Iqani and Schroeder, 2016, p. 409). In their study of communal cooking via YouTube videos, Paay, Kjeldskov, Skov, and O’Hara (2013, p. 6) suggest digital ethnography allows researchers to "immerse themselves in the digital world rather than physical and make use of digital data, such as written words, images, audio files, video and online communities, about the phenomenon of interest, which is often available in vast amounts today." Similarly, YouTube surprise vacation reveal videos capture children's voices and family interactions (e.g., body language, communication) in the moment. Specifically, data for this study include videos in which children are being surprised with sudden family vacations.

\section{Data Collection Procedures}


Purposeful sampling was used to identify and select relevant videos (Patton, 2002). Predetermined sampling criteria directed the selection process. First, appropriate search terms and phrases were used to guide the sampling process. In line with previous research methods (Snelson, 2015), initial test searches were conducted on YouTube to identify the most relevant search phrases. Successful search terms included "surprise family holiday," "surprise family vacation," "surprise vacation for kids," and "surprise holiday for kids." The goal was to uncover a variety of experiences in which children were the recipients of surprise family vacations. Snowball sampling was then used as YouTube suggested similar content to previously watched videos. For instance, while watching a video titled "Surprise Disney Holiday from UK," YouTube suggested other videos on the right-hand side of the screen, such as "Surprise Disney Holiday FAIL!" and "Surprise UK Holiday Reveal." Second, diversity in family demographics was sought. All searches were conducted in English; however, family videos were sought from a variety of English-speaking countries and from a variety of ethnicities. As a proxy for socioeconomic status, the search process pursued a variety of vacation destinations. That is, some families may take surprise one-day trips to local theme parks while others may take more seemingly extravagant excursions, such as week-long trips overseas. Diversity was also sought in the ages of children featured in the videos. In some cases, children's ages were provided in the description section of each video or in the dialogue of the video. To estimate children's ages in videos in which their ages were not explicitly stated, two independent coders provided estimates of the children's ages and an average was taken. Third, all selected videos in the sample were "day-of" surprises, in which the family left for a vacation within 24 hours of the surprise. In other words, the sample only includes videos in which the family left on the same day or the day after the surprise vacation reveal. 
These procedures resulted in a sample of 139 online surprise vacation reveal videos. Data collection resulted in 13 hours, 46 minutes, and 30 seconds of video, with the median video lasting 3 minutes and 57 seconds. The shortest video was 46 seconds. The longest was 35 minutes and 51 seconds. Each video was watched several times, and all video content (e.g., dialogue, setting, description of action) was transcribed verbatim. All videos in the sample are in the English language; however, the videos originate from a range of geographic regions, with families from the Australia, Canada, England, Ireland, and the United States represented in the sample. Table 1 provides a descriptive summary of a subset of ten videos to demonstrate the contextual diversity of the data. Through analyzing the visual elements and verbal discourses of the YouTube surprise family vacation reveal videos, the study captures families authentic lived experiences, as they unfolded in real-time.

\section{Data Analysis Procedures}

Data analysis combines a hermeneutical approach of interpretation, as outlined by Thompson (1997), with traditional principles of grounded theory interpretive research (Corbin and Strauss, 2015). This combined qualitative technique allows themes to emerge iteratively from the data, while simultaneously drawing insights relative to previous literature (Arnold and Fischer, 1994). The interpretive process centers on coding the data. Coding is a process which involves breaking the data apart into discrete concepts, or categories (e.g., open coding), clustering the concepts based on conditions, context, strategies, and outcomes (e.g., axial coding), and reconfiguring these categories into a higher level of abstraction, or conceptual integration (e.g., selective coding; Spiggle, 1994; Corbin and Strauss, 2015). This interpretive 
process results in a coherent emergent conceptual framework, in which details from case to case may differ but the proposed relationships among concepts remain consistent at an abstract level.

For this study, the coding process began with identifying recurring themes in both the visual elements of the videos (e.g., physical interactions between family members, material props) and the textual data derived from the videos (e.g., discourses and meaning embedded in the transcripts). The goal is not to argue for or against surprise family vacations, but rather, to generate meaning from data (Miles and Huberman, 1994). The data were first analyzed, using open coding, within each video, accounting for each individual family's nuanced experience. Then, the videos and accompanying transcripts were compared and contrasted across the data, aiming to identify clusters and more abstract theoretical integration. Memos were created throughout the process to track analytical insights. Through a constant comparative method, both within and across the videos, themes were refined (Corbin and Strauss, 2015). The interpretations developed over multiple readings and viewings of the data. Data analysis was deemed complete when a conceptually dense conceptual framework emerged. To build confidence in the emergent findings, three parents who had each previously surprised their children with a family vacation reviewed the findings and discussed the interpretations with their children (five children total; ages ranging from 5 to 14 ) to verify the analysis. These families corroborated the analysis, and no contradictory information emerged.

Insert Table 1 Here

\section{FINDINGS}


Performing a surprise family vacation reveal is an interactive process of social drama, executed by the actors (e.g., parents, children) playing various roles. Albeit, children are unknowingly actors in the performance until it is unfolding, whereas parents have advance notice. The surprise vacation reveal captures the liminal moment in which a child discovers he or she will be going on vacation. In this case, performing encompasses the processes involved in young consumers embodied experiences as they unexpectedly become tourists. The data suggest surprise family vacations center on three primary performance practices: executing the reveal, announcing the destination, and reacting to the surprise. These performance practices capture the rising and falling action of the performance, with the climactic moment occurring when the destination is officially announced in the midst of the surprise vacation reveal.

As young consumers instantly shift from non-tourists to tourists, surprise vacation reveal videos illustrate their embodied experiences of transitioning to a touristic identity—reflected in their experiences and enactments. Indeed, by nature, tourist performances require adaptations and fluidity (Larsen and Urry, 2011); however, this study reveals pressures and anxieties may arise as such adaptations are made. Drawing on performance theory, findings suggest surprise family vacations can give rise to embodied tensions between culturally-shaped normative expectations (i.e., intended and expected outcomes) and families' unanticipated lived experiences (i.e., unintended and unexpected outcomes), at each stage in the unfolding social drama. Norms suggest the surprise reveal will be executed flawlessly, and children will instantly and excitedly embrace their new identities as tourists. Yet, this is not always the case. Children may react unexpectedly or reveal their own anxieties about travel. Thus, surprise family vacations are characterized by three performance practices in which tensions arise between 
normative expectations and unanticipated experiences: executing the reveal (scripted act versus improvised act), announcing the destination (absolute ideal versus relative ideal), and reacting to the surprise (initial acceptance versus initial rejection). Table 2 provides a framework of performance practices and embodied tensions as the performance unfolds. The findings are reported using pseudonyms, using evidence from the data to illustrate.

Insert Table 2 Here

Executing the Reveal: Embodied Tension between Scripted Act versus Improvised Act

Executing the surprise vacation reveal represents the rising action of the performance. Parents enter into the surprise vacation reveal with expectations of how the performance will be executed. In contrast, children are largely unaware of their role in the execution until the surprise is unfolding. The surprise itself is highly scripted—often requiring props and advance planning. However, the scripted performance can become an act of improvisation as plans go awry (e.g., children do not respond as expected, plans are disrupted). Thus, the data reveal a tension between the normative expectation of scripted performances versus the unanticipated experience of improvisation. Parents feel pressure to create a memorable moment in time, with high production value and prepared scripts. In one YouTube video, a British husband and wife pick up their three young daughters (Imogen, age 6; Hailee, age 7; Evie, age 11) from school to surprise them with a trip to Amsterdam. Their mother, Katherine, discusses her best laid plans:

\{Katherine speaking to camera as husband packs the car in the background.\} 
Katherine (mother): [We need to] go pick up the girls from school. Surprise them. Have no idea how. [...] I'll be so glad when we're finally there, then we can relax. No idea how we're going to surprise the girls. Haven't had a chance to even wrap [their] presents. Haven't had a chance to get their neck pillow, cute things. I had this vision in my head, you know that when you fly you can get those pillows that go 'round your neck that are really cozy? My girls have been desperate for one of those for so long, and I bought them one for this trip. And I wanted them all cutely laid out on their seats, get them all some snacks and it'd look really cute, so when they came to the car, they kind of knew what we were doing. But that's not going to happen. I don't even know where the pillows are, in a bag, somewhere in the boot.

Katherine's experience underscores the pressures families, especially mothers, feel to plan an exciting reveal. Families create scripted scenes in which their children are both actors and audience members. In Katherine's case, she purchased travel pillows for her daughters and imagined how she would stage the surprise. On the day of, she and her husband are behind schedule, and despite having a scripted plan in mind, they end up announcing the trip to the girls on the way to the airport - using no gifts or gimmicks. This ad-libbed approach exposes the reality of executing a surprise family vacation, which can be disordered and disrupted as a result of day-to-day family pressures (e.g., running late) and other travel-oriented responsibilities (e.g., packing, arriving on time to the airport). Even without the perfectly executed performance, Katherine's three daughters are thrilled with the surprise trip, with the youngest crying tears of joy.

Surprising children with a family vacation often involves props such as destination themed gifts, scavenger hunt clues, boarding passes, destination maps, among others. Parents expect these props to be self-explanatory. In other words, kids should 'get it' right away. As Katherine said, she expected her daughters to see the travel pillows and "kind of [know] what [they] were doing." Using props allows families to provide a level of tangibility to an intangible, 
experiential surprise. Olivia, a mom of three daughters (Emily, age 14; Erin, age 12; Eliza, age 9), films her children's reaction to a surprise trip to Disney World:

\{Olivia speaking to camera before children arrive home\}

Olivia (mother): So, we have the surprise set up. One in each room. Just waiting for them to get off the bus.

\{Olivia walks into each room. On each bed are t-shirts that say: "I can't keep calm, I'm going to Disney," along with balloons, stuffed animals, Mickey Mouse ears, and customized cards for each child saying "We're going to Disney World tomorrow!'\}

Olivia (mother): I'm gonna pause now, and come back when they come in the door.

\{Cut to kids coming in the front door of the house.\}

Olivia (mother): We did a little project in your rooms. So, take your coat and your bookbag off. We're going to do a surprise now.

Emily (daughter): What is this?

Olivia (mother): Wait, you've got to all stand by your doors.

Alec (father): It's for everybody. Take your coats off, and stand by your doors.

Olivia (mother): On the count of three, you open your door and turn your light

on.

Alec (father): Okay, go down the hall. Now don't go in until your sisters get there too.

\{Three girls each stand by their closed bedroom doors.\}

Olivia (mother): Okay, you ready? 1-2-3-go.

\{Each girl opens her bedroom door and walks in silently as the parents wait, filming, in the hallway. The girls emerge from their room, appearing confused.\}

Olivia (mother): Do you know what it is?

Emily (daughter): Wait what?

Eliza (daughter): Are we going to Disneyland?

Emily (daughter): Wait what?

Olivia (mother): We're going to Disney World tomorrow. We've kept this from you since before Easter.

\{Youngest daughter screams; two teenage daughters remain in shock.\} 
For parents, like Olivia, executing a surprise family vacation is a highly-scripted occasion. Props, like the mouse ears and the t-shirts, offer a way to symbolically represent the trip. Parents do not have control over their children's interpretations of the props. As Olivia's oldest daughter, Emily, repeatedly asks, "Wait, what?" Young consumers do not always catch on immediately. Emily, Erin, and Eliza each received customized cards explicitly stating, "We're going to Disney World tomorrow!"- yet, in a state of confusion and shock, they needed their parents to confirm and further explain. In this way, props act as tangible proof or evidence of the trip. In the data, children consistently respond with incredulous remarks like, "You're lying" and questions like, "Are you serious? Are we really going?" In turn, parents offer items like printed boarding passes, hotel reservations, and admission tickets/passes to prove they are indeed going on a surprise trip. In this way, what was intended to be a scripted performance turns into improvisation, as children's reactions vary widely and parents must adapt.

Lastly, technology mediates how surprise vacation reveals are executed. Parents turn to technology to support their surprise vacation efforts, by recording their children's reactions in order to create a lasting record of the performance. In some cases, technology is used to execute the reveal itself. For instance, one family hires an actress to personify Princess Anna, from the Disney movie Frozen. The actress records a video inviting the family's three children, by name, to visit her in Disney World. This not only reflects the scripted nature of the surprise vacation reveal but also demonstrates how technology can be used to support the reveal itself. Sometimes the use of technology nearly upends the surprise. In some cases, filming the surprise vacation reveal interferes with the authenticity of children's reactions or places them on-guard. Before being surprised with a day-trip to the local theme park, one young girl ( age 10) says, "I can tell you're video-taping me. Anytime the camera's on, there's something happening." The reality- 
television-like approach to the surprise vacation reveal signals to children that something of significance is about to occur. Other technologies can also interfere with the surprise. In one video, a mother tells her three young children they are going to the grocery store; however, the mom intends to surprise them with a day at a local theme park. Before the mother can execute the big reveal, the GPS navigation system in her car announces, "In one mile, your destination will be on the right." The mother says the GPS is wrong and they really are going to the store, but her children do not believe her. Indeed, in surprise vacation reveals, parents have a script in mind - visions of how the reveal will be executed and expectations for how their children will react. For children, they are the recipients of the surprise and not privy to their expected performance roles. Thus, the lived experience of surprise family vacations becomes improvisational.

\section{Announcing the Destination: Embodied Tension between Absolute Ideal versus Relative Ideal}

Be it a day-trip to a local amusement park or longer trip to a foreign country, announcing the destination is the climax in the surprise family vacation performance. The underlying normative expectation in surprise family vacations suggests there is an absolute ideal destination. That is, parents expect the destination they have selected is preferred to all others, with stereotypical family-oriented destinations (e.g., Disneyland, Disney World, Universal Studios) considered the objective 'best.' In many cases, parents are correct, and their children are thrilled with the trip they have planned. However, an embodied tension emerges when children's perceptions of the selected destination do not align with normative expectations.

Comparison accentuates this tension between absolute and relative perceptions of surprise destinations. Parents, for better or worse, often use a hierarchical positioning of desired 
destinations - pitting locales against one another, explicitly or implicitly. Susan and Alan told their two pre-teen sons they were going to Miami for the weekend; yet, on the drive through Florida, they arrived at their true destination, Universal Studios. Their younger son, Brandon ( age 10), thrilled by the turn of events, proclaims his parents are "the most amazing people of the century" and says, "This is the best news of the century. I feel so excited!" Brandon's performance falls in line with his parents' normative expectations of family vacation destinations. His parents are thus positioned as the heroes, and in turn, Brandon and his brother, albeit, to a less vocal extent, are grateful and happy children. Brandon's family used a "bait and switch" strategy to trick their young sons into thinking they would be going on a trip to Miami, then surprising them with a perceivably better destination-Universal Studios. The premise being, Universal Studios is the absolute preferred vacation destination.

Many families use this type of comparative, bait and switch tactic, in which they say they are heading to one location and surprise the kids by, in fact, going somewhere else. Parents promise a more seemingly mundane vacation and assume that a vacation like a cruise or a trip to Disney will outweigh the switch. In Brandon's case, this trick worked successfully; however, the data suggest these big-ticket, idealized destinations do not always trump promised destinations. For several weeks in advance, Spencer and Molly told their two children, Jillian ( age 7) and Owen ( age 4), that they were going on a trip to Chattanooga, Tennessee-a seemingly less exciting destination than their actual one, Disney World. Jillian and Owen have unexpected reactions:

Molly (mother): We were talking and I know you guys have really been looking forward to going to Chattanooga. Owen, you listening? I know you guys have really been looking forward to going to Chattanooga but Daddy and I talked about it, and we don't think we want to go.

\{Jillian and her mom banter.\} 
Molly (mother): I thought we'd go somewhere else instead.

Jillian (daughter): No. Where? ... Where?

Molly (mother): Where would you guys like to go instead?... I thought we'd go to Disney World.

Jillian (daughter): No, mommy.

Molly (mother): What?!

Owen (son): Mommy, you don't want to go to Chattanooga?

Molly (mother): Well, Daddy and I are going to Disney World.

Jillian (daughter): Mommy —we are going to Chattanooga! Stop!

Spencer (father): Are you kidding me?

Molly (mother): I've already made reservations for breakfast with the

princesses, and to get our hair done at the Bippoty Boppity Boutique.

Jillian (daughter): Mommy, are we really going there?

\{Jillian begins to cry.\}

Spencer (father): I have never heard anyone cry because they're going to Disney World-

Molly (mother): Instead of Chattanooga, ha.

Spencer (father): Instead of Chattanooga.

Jillian (daughter): I want to go to Chattanooga, not Disney World.

Even when the surprise destination is Disney, it pales in comparison to the promised destination of Chattanooga. This comes as a shock to Jillian and Owen's parents, who begin to cite the fun child-centered activates they have planned, such as the princess breakfast. Despite Disney seeming more child-centered and idealized than Chattanooga, Jillian in particular is attached to the previously promised destination. Indeed, children unexpectedly approach their vacation destination with an attitude of relativity. They consider what has been promised already, or what they have built up in their minds, and use it as a reference point to frame the unexpected news of a surprise destination.

Culturally-shaped norms suggest destinations like large theme parks (e.g., Disneyland, Universal Studios) and cruises will trump all other tourist destinations and even, in some cases, other more mundane excursions like a business trip with parents or a grandparent's house. By framing the surprise vacation in reference to other tourist destinations and excursions, parents 
produce an underlying hierarchy of desired destinations. That is, some vacations are inherently and objectively better than others. Such expectations influence how young consumers experience surprise (see Bartsch and Estes, 1997). For young consumers, indeed some vacations are preferred over others, but children's preferences may not be as predictable as cultural norms suggest. In some cases, children's imaginations can lock onto a destination—without prompting. For instance, in one video, parents, Ron and Kimberly, told their 5-year-old twins, son Jackson and daughter Vee, that they "were going on a surprise trip." They film their children's reactions in the backseat of the car, as they approach the entrance gate to Disney World; however, their son's reaction is unexpected:

Kimberly (mother): We're taking y'all to Disney World!... Jackson, how come you're not smiling?

Jackson (son): Because I wanted to go to Chuck E. Cheese.

Kimberly (mother): Chuck E. Cheese is worse than Disney World. Disney World is the best. [...] We're gonna stay in a nice resort area, and it's gonna be so much fun. And we're gonna enjoy the ride into Disney World.

Jackson (son): What are we gonna ride on, nothing?

Ron (father): Jackson, Disney World's got a bunch of rides.

Kimberly (mother): Disney World has so much.

Ron (father): Would you rather go to Chuck E. Cheese or Disney World?

Jackson (son): [looks down, quiet and reluctant] I want to go to Disney World.

Ron (father): I'm glad, because we're gonna have a good time. We're not gonna let you spoil our good time.

In Jackson's mind, the surprise family trip was going to Chuck E. Cheese, an indoor arcade franchise, but he is distraught when the destination turns out to be Disney instead. Jackson's mother uses a strategy many parents enact when a surprise vacation reveal goes awry—damage control. Kimberly attempts to convince Jackson that Disney World is a better option. At the end of the video, Jackson's father, suggests his son should regulate his emotions for the sake of the family's fun experience. Ron's comment is not out of the ordinary. When their children do not react in the expected way to the surprise vacation destination, they are disappointed. They make 
comments referring to the cost of the trip (e.g., "We spent a lot of money on this. You're supposed to be happy.") or suggesting the trip can be cancelled or changed at a cost to others (e.g., "Everyone else is excited, but we don't have to go if you don't want to."). In fact, Jackson's mother notes they "could have saved a lot more money had [they] known!" Normative expectations propose Disney, or other similar, extravagant children-centered trips, objectively trump all other destinations; however, when the destination is announced, children may unexpectedly use atypical, relative anchors (e.g., mundane or imagined destinations). Across the data, children express confusion and disappointment when the destination is not what they expected. In line with previous research, parents quickly prompt their kids to regulate their emotions (see Kieras, et al., 2005).

Reacting to the Surprise: Embodied Tension between Initial Acceptance versus Initial Rejection

Inherent in the in the surprise vacation reveal is both the element of shock and the idealized expectation that children should be excited, grateful, and accepting of the surprise. Indeed, many videos show children screaming, crying, and thanking their parents; however, others are far more skeptical and confused by the surprise. The surprise vacation reveal performance closes with the practice of reacting to the surprise. Within the practice, an embodied tension arises between initial acceptance and initial rejection. By parents taking sole ownership of the planning process in surprise family vacations, the normative expectation is they are liberating their children from the responsibilities of planning. The role of the child is to be a grateful recipient, with no responsibilities other than having fun. While many kids react with excitement, as expected, others are initially startled by the disruption their regularly structured schedules. When parents surprise their children with a family vacation, they expect it will be 
perceived as an exciting escape from the children's day-to-day routines; however, some children, when told they are going on a sudden surprise vacation, react with questions and behaviors that reflect practicality. For instance, Stacy and her husband Lucas plan a surprise Halloween trip to Disney World for their two young children, Harrison (age 4) and Harper (age 6). Despite the allure of Disney World, Harper reacts with disappointment over missing her special Halloween dance class. Well-meaning parents assume a surprise vacation will be a welcomed and exciting escape, but for children, it can be perceived as a disruption to their routines. Across the data, children ask questions and express concerns about missing school activities and missing extracurricular activities. One child is worried about missing her physical fitness test as school. Another is concerned about missing weekly dinner with her grandmother. Younger children seem to be more concerned about disruptions to their routines; however, older children also express frustration from being kept in the dark. As one teen asks her parents, "Why didn't you tell me, so I could tell my friends I'm gonna be gone?"

Parents may not understand or anticipate concerns and questions children will have about travel. Acknowledging children's fears or practical concerns is a challenge when a vacation is sprung on them. Parents may believe they are freeing them from the trivial details embedded within trip planning, but in many cases, children have legitimate questions. For Cole's 6-year-old birthday, his parents promise him a day of fishing on the lake but surprise him with a trip to Six Flags, a popular American amusement park. Upon arrival, Cole proceeds to express very practical concerns, from concerns about his wardrobe (e.g., "I don't even have a bathing suit") to the cost of the excursion (e.g., "[Six Flags] is real expensive though). Given the surprise-oriented nature of the trip, Cole's questions have gone unaddressed and, instead, they all emerge at once. When parents plan surprise family trips, particularly day-of excursions, children are not involved 
directly in the planning. Thus, their fears and anxieties may be overwhelming in the midst of the surprise performance. Many children in the data readily welcome the surprise trip, with no questions while others are more inquisitive and anxious after finding out about the surprise trip. Across the data, children's concerns relate to preparedness (e.g., "Who will watch the dog?" "Did you pack my favorite stuffed animal?" "Did you pack my iPod?"), logistics (e.g., "Where are we staying?" "How long is the flight?"), retrospective verification (e.g., "Is this why we got passports?" "Is this why you made me pack extra pajamas"), and finances (e.g., "Does this mean we're rich?" "But you said it was too expensive."). Perhaps, to parents, a benefit of surprising children with vacations is avoiding perceivably nagging questions (e.g., How many more days until we leave? Can I bring this toy?). However, these questions, which emerge simultaneously in the midst of surprise family vacations performances, can be daunting for a young child. For example, one couple surprises their children, Thomas (age 7) and Luis (age 9), on Christmas morning with a trip to Disney World. The boys unwrap boxes filled with Disney themed gear and a note announcing the trip:

Thomas (son): What! Is this Disney stuff?

Mary (mother): Surprise, you're going to Disney.

Thomas (son): Oh my God, we're going to Disney.

Mary (mother): You kept asking and we've been trying not to tell you for the longest time.

Thomas (son): Yay, we're going to Disney. \{Thomas gets off of the couch and does a happy dance.\} We're going to Disney. Really? But why are we going to Disney?

Mary (mother): Because we thought it would be fun.

Thomas (son): Finally in the winter we can go somewhere warm!

Randall (father): Luis, are you happy?

Mary (mother): \{to Luis\} Are you speechless?

Luis (son): We're gonna fly in a plane to-we're gonna crash and die!

Mary (mother): Oh, my god, thanks to the media for all of that attention.

Thomas (son): What if I throw up on the plane?

Mary (mother): I don't think you're gonna have to worry.

Randall (father): They'll clean it up. They have special bags for that.

Thomas (son): I don't want to go. 
Luis (son): No, I don't want to die.

Mary (mother): I think you're the only kids \{trails off\} ... Other kids on video are like, "Woooo, we're going to Disney!" Mine are like, "We're really going? Well I might throw up on the plane."

Thomas (son): But I will.

Luis (son): We're gonna crash and die.

Luis is clearly concerned about going on an airplane and repeatedly mentions a fear of dying in a plane crash. His mom blames the media, and indeed, later in the video, Luis insists a crash could occur because it "happened on TV." For contextual reference, Luis and Thomas's Disney World surprise took place on Christmas Day in 2014. In March 2014, Malaysia Airlines Flight 370 went missing, and four months later, Malaysia Airlines Flight 17 was shot down over Ukraine. Both incidents received extensive news coverage. Although Luis may have never previously expressed a fear of flying, he internalized the images seen on television and developed a fear which readily emerged in the midst of the surprise family vacation reveal. Subsequently, Luis's younger brother, Thomas, expresses a concern about throwing up on the flight. Although Thomas is overall excited about the trip, his brother's fears influence him, and Thomas begins to second guess the vacation. Interestingly, the boys' mom makes reference to normative behavior that "other kids on video" display—a testament to ubiquitous nature of surprise family vacation reveal videos and the expectation of kids viewing the experience as an exciting escape. Thomas and Luis, in contrast, are overcome by concerns, which seem very legitimate in their own minds. Although surprise family vacations may seem to free children from the minutiae of family vacation planning and preparation, it also suppresses their agency in discussing fears or concerns in advance.

\section{DISCUSSION}


Surprising children with family vacations is not a new phenomenon; however, the pervasiveness of social media and video-capturing technology increasingly provides a stage for families to immortalize the drama of the 'big reveal' performance. When revealing surprise family vacations, families perform romanticized practices that are shaped by cultural ideals and expectations. The overarching normative expectation is that children will be grateful recipients of the surprise vacation experience. However, drawing from previous work on performance in tourism, this study unveils the embodied tensions that can arise as families enact performance practices in surprise family vacations - executing the reveal, announcing the destination, and reacting to the surprise. As children's actual behaviors and reactions misalign with culturally shaped expectations, this study reflects a snapshot of how families discuss tourism related topics, in situ. The findings of this study hold implication for performance theory and child-centered tourism perspectives, for marketers and parents, and for methodological approaches in researching family tourism.

\section{Theoretical Implications}

This research extends existing literature on performance theory in tourism by revealing children's embodied experiences of becoming tourists. Positioning a family vacations as an offering or surprise for the children is distinct from previous research, which suggests family vacations are co-created and motivated by parents' desire for escape (Gram, 2007; Kang, Hsu, and Wolfe, 2003). Surprise gifts are considered superior to anticipated gifts (McGrath, Sherry, and Levy, 1993); however, in the experiential context of surprise family vacations, unanticipated risks may emerge in waiting to tell children about a vacation until the night- or day-of departure. These findings further reinforce ways in which tensions emerge in family vacations, particularly 
for mothers (Backer and Schänzel, 2013). Extending this research, the current study demonstrates how children embody stresses in the midst of vacationing as well. In the context of surprise family vacations, children are not directly involved in trip planning discussions. Their anxieties and questions about travel emerge all at once in the midst of the surprise vacation reveal. As children age, they become more directly engaged in family tourism decisions (Thornton, Shaw, and Williams, 1997). Extending Singh and Nayak's (2014) work, this research offers a real-time snapshot of how children, of many ages, engage in family tourism conflicts around logistics, preparedness, and other elements of a family trip, which also likely take place prior to a non-surprise family vacation. Younger children seemed more concerned about logistics (e.g., missing events, flying on an airplane), but they were also more likely to respond with very thrilled, overjoyed, emotional reactions. Perhaps this suggests older children are better at regulating their emotions and are less likely to experience surprise, supporting previous research (Bartsch and Estes, 1997; Kieras, et al., 2005).

Tourist performances are created through anticipating future vacations and reflecting on past ones (Bærenholdt et al., 2017). Relative to their adult counterparts, young consumers have limited previous vacationing experience from which to draw. While this study is not explicitly centered on communication strategies, its findings offer evidence of how families communicate about vacations - particularly questions and concerns that young children may have. The surprise family vacation reveal is expected to be highly choreographed and readily accepted by children. In reality, the performative display may face push back from children who may express fears, frustration, and skepticism. Thus, the underlying motives for parents to surprise their children with family vacations may result in unintended consequences when children do not react in the preferred scripted manner. In contrast to previous work on family tourism, surprise family 
vacations capture instances in which children are intentionally removed from the family holiday planning process. In Gram's (2007, p. 23) study of children as co-decision makers in the family vacation planning process, one parent notes, “...it is of course also easier to implement [a family holiday] and the enthusiasm is of course completely different than if we had forced [our daughter] onto a holiday." Indeed, forcing children into a family vacation undermines parents' desires to please their children and create positive travel moments for them ( $\mathrm{Li}, \mathrm{Wang}, \mathrm{Xu}$, and Mao, 2017). Yet, surprise family vacations are paradoxically forced upon children. Guided by the belief that children will be grateful beneficiaries of a surprise trip, parents handle all of the tasks and activities leading up to the family vacation. One might assume parents have the sole burden of stressors in surprise family vacations; however, as demonstrated by the findings, children experience tourism-related stresses as well.

\section{Practical Implications}

Children are becoming more sophisticated tourism consumers, and modern families increasingly seek experiential vacations (Schänzel and Yeoman, 2015). This study offers a foundational point from which future research might examine performance and embodied experiences in the context of family tourism. Material and performative practices of family vacations begin even before a family enters its tourist destination. In line with previous work on performance in tourism (Bærenholdt et al., 2017; Coleman and Crang, 2002; Edensor, 2000), anticipation is a key element in family tourism. Surprise family vacations limit the duration of and opportunity for anticipation among children. In contrast, parents anticipate and look forward to the surprise vacation reveal itself. Surprise family vacations become an impetus for marketplace purchases, as parents prepare a big reveal for their children. They rely on offerings 
such as stuffed animals of Disney characters, pre-purchased boarding passes, and other products to assist in tangibilizing the vacation prior to its official start. Families also turn to marketplace services, such as the instance in which a Princess Anna actress was hired to pre-record a custom video. Service providers and retailers may provide offerings for families to easily plan surprise family vacations.

In today's family tourism consumer culture, an increased pressure is placed on parents to not only plan a memorable vacation but also to plan an exciting reveal. In turn, children may not have a reference point for how they are supposed to behave or react. Cullingford (1995, p. 121) states, children "submit to whatever choices their parents make, and that they have little secondary influence on their parents' particular choice of holiday destination." While that may be true, the findings presented here demonstrate the nuanced and tense conversations families may have as children submit to their parents' choices — even when the destination is a culturally idealized one (e.g., Disneyland, Universal Studios). Parents should be mindful of their children's unique personalities and potential reactions, as kids may feel confused, or even betrayed, when vacation plans are announced unexpectedly. Parents might also consider how they discuss vacationing with their children, in general, prior to a surprise vacation. Talking points might include: How would you feel if we went on a sudden vacation? Where would you like to go on a vacation? What would be important things to pack for a vacation? Parents might also gauge how their children feel about potential disruptions to their routine (e.g., missing school) or travelbased fears (e.g., going on an airplane). Lastly, parents should recognize that 'successful' surprises are subjective, and a variety of factors might influence children's reactions.

\section{Methodological Implications}


Family tourism research has a methodological tendency to ask parents with young children to voice their adult perspectives, rather than capturing the experiences of the children themselves (Khoo-Lattimore, 2015). That is, children's voices in family tourism research are largely absent (Poria and Timothy, 2014). Methodologically, this paper reveals the experiential insights which can be garnered from YouTube. YouTube is unique in that it makes publicly available what is often privately experienced. Prior to the advent of social media, videos like the ones used in this study would have been stored away in family homes - in drawers under the television or a box in the garage. YouTube provides a platform for researchers to examine consumers' lived experiences as they happened. In the context of researching young consumers, this is particularly exciting given the challenges of capturing children's authentic voices (Banister and Booth, 2005; Cody, 2015). New mediated technologies offer a frontier for marketing scholars to examine young consumers' lived experiences. With an increase in 'sharenting' culture, families are increasingly sharing the day-to-day experiences of their children (Steinberg, 2016). Notably, children are increasingly turning to social media platforms to share their own lived experiences, independent of their parents. Social media platforms offer potential for capturing young consumers' voices, in their real-time lived experiences. That is not to say researchers should exploit children and families' online lives, without restraint. Ethical debates and privacy concerns accompany the rights of children in online spaces (Canosa and Graham, 2016). Scholars must weight considerations for children's privacy and safety protections above the appropriateness of social media platforms (e.g., YouTube) as data collection sites.

\section{LIMITATIONS AND OPPORTUNITIES FOR FUTURE RESEARCH}


The current study centers on analyzing the moment in which children discover they are going on a surprise family vacation. While this approach captures a lived moment in time, it is limited by overlooking potential antecedents and consequences of surprise family vacations. That is, why might parents choose to surprise their children? What antecedents might influence children's reactions? Similarly, how do families' experiences on vacation unfold following a surprise vacation reveal? How do families cope with tensions over time, not just in the moment? Future research might take an experimental approach to better understanding young consumers' perceptions of surprise vacations versus non-surprise (e.g., planned) vacations. More holistically, to understand families' experiences over time, future research should use longitudinal qualitative methods (e.g., interviews, ethnography) to investigate young consumers' and parents' tourism experiences in situ. Such integrated methods would offer a contextualized perspective of surprise family vacations and their evolution over time.

Additionally, the current study only explored videos posted to YouTube, when in fact, many families may record their experiences but choose not to post them online, or may choose to post them on more private social media sites (e.g., Facebook, Instagram). Videos uploaded publically to YouTube may only represent the cutest, funniest, or most endearing experiences. Recognizing this potential bias in the platform, future research should better understand why and how families choose to share their tourism related experiences, across a variety of platforms. Why do some videos and photographs make the cut when others do not? As social media and video recording tools become increasingly ubiquitous, particularly as tech-savvy Millennial parents come of age, it is important to understand how technology and shareability influence family tourism experiences. The current paper aims to focus on the children's experiences, in the 
moment; however, future research might build on this study to address why parents engage in 'sharenting' practices around tourism, and how such shared, technology-mediated experiences influence family tourism. 


\section{REFERENCES}

Aleti Watne, T., Brennan, L. and Winchester, T.M. (2014), "Consumer socialization agency: implications for family decision-making about holidays, " Journal of Travel \& Tourism Marketing, Vol. 31, No. 6, pp.681-696.

Arnold, S. J., and Fischer, E. (1994), "Hermeneutics and consumer research,” Journal of Consumer Research, Vol. 21, No. 1, pp. 55-70.

Bærenholdt, J. O., Haldrup, M., Larsen, J., and Urry, J. (2017), Performing Tourist Places, Routledge, New York, NY.

Backer, E., and Schänzel, H. (2013), “Family holidays_-Vacation or obli-cation?," Tourism Recreation Research, Vol. 38, No. 2, pp. 159-173.

Banister, E. N., and Booth, G. J. (2005), "Exploring innovative methodologies for child-centric consumer research," Qualitative Market Research: An International Journal, Vol. 8, No. 2, pp. 157-175.

Bartsch, K. and Estes, D. (1997), “Children's and adults' everyday talk about surprise,” British Journal of Developmental Psychology, Vol. 15, No. 4, pp.461-475.

Canosa, A., \& Graham, A. (2016), "Ethical tourism research involving children," Annals of Tourism Research, Vol. 61, No. 4, pp. 219-221.

Chenail, R. J. (2011), "YouTube as a qualitative research asset: Reviewing user generated videos as learning resources," The Qualitative Report, Vol. 16, No. 1, pp. 229-235.

Cody, K. (2015), "Hearing muted voices: The crystallization approach to critical and reflexive child-centric consumer research,” Young Consumers, Vol. 16, No. 3, pp. 281-300.

Coleman, S., and Crang, M. (2002), Tourism: Between Place and Performance, Berghahn Books, New York, NY.

Corbin, J., and Strauss, A. (2015), Basics of Qualitative Research, SAGE Publications, Thousand Oaks, CA.

Coleman, S., and M. Crang, eds. (2002), Tourism: Between place and performance. Berghahn Books.

Cullingford, C. (1995), “Children's attitudes to holidays overseas,” Tourism Management, Vol. 16, No. 2, pp. 121-127.

Dinhopl, A. and Gretzel, U. (2016), "Selfie-taking as touristic looking," Annals of Tourism Research, Vol. 57, No. 3, pp.126-139.

Edensor, T. (2000), "Staging tourism: Tourists as performers," Annals of Tourism Research, Vol. 27, No. 2, pp. 322-344. 
Ek, R., Larsen, J., Hornskov, S. B., and Mansfeldt, O. K. (2008), “A dynamic framework of tourist experiences: Space-time and performances in the experience economy," Scandinavian Journal of Hospitality and Tourism, Vol. 8, No. 2, pp. 122-140.

Foxman, E.R., Tansuhaj, P.S. and Ekstrom, K.M. (1989), "Family members' perceptions of adolescents' influence in family decision making," Journal of Consumer Research, Vol. 15, No. 4, pp.482-491.

Goffman, E. (1959), The presentation of self in everyday life, New York: Anchor Books.

Gram, M. (2005). "Family holidays. A qualitative analysis of family holiday experiences," Scandinavian Journal of Hospitality and Tourism, Vol. 5, No. 1, pp. 2-22.

Gram, M. (2007), "Children as co-decision makers in the family? The case of family holidays," Young Consumers, Vol. 8, No. 1, pp. 19-28.

Hastings, D. (2013), "Little girl who was Internet sensation loses it again when parents say, 'We're going to Disneyland!' - but her 2-year-old sister is not amused," Daily News, accessed at: http://www.nydailynews.com/news/national/girl-internet-darling-joyous-sobbing-meltdowntoddler-sister-steals-show-time-article-1.1468394.

Iqani, M. and Schroeder, J.E. (2016), “\# selfie: digital self-portraits as commodity form and consumption practice, Consumption Markets \& Culture, Vol. 19, No. 5, pp.405-415.

Kang, S. K., Hsu, C. H., and Wolfe, K. (2003), "Family traveler segmentation by vacation decision-making patterns," Journal of Hospitality \& Tourism Research, Vol. 27, No. 4, pp. 448469.

Kensbock, S., Jennings, G., Bailey, J. and Patiar, A. (2016), "Performing: Hotel room attendants' employment experiences," Annals of Tourism Research, Vol. 56, No. 1, pp.112-127.

Khoo-Lattimore, C. (2015), "Kids on board: Methodological challenges, concerns and clarifications when including young children's voices in tourism research," Current Issues in Tourism, Vol. 18, No. 9, pp. 845-858.

Khoo-Lattimore, C., Prayag, G., and Cheah, B. L. (2015), "Kids on board: Exploring the choice process and vacation needs of Asian parents with young children in resort hotels," Journal of Hospitality Marketing \& Management, Vol. 24, No. 5, pp. 511-531.

Kieras, J.E., Tobin, R.M., Graziano, W.G. and Rothbart, M.K. (2005), "You can't always get what you want: Effortful control and children's responses to undesirable gifts," Psychological Science, Vol. 16, No. 5, pp. 391-396.

Larsen, J. (2005), "Families seen sightseeing: Performativity of tourist photography," Space and culture, Vol. 8, No. 4, pp.416-434.

Larsen, J., and Urry, J. (2011), "Gazing and performing," Environment and Planning D: Society and Space, 29(6), 1110-1125. 
Li, M., Wang, D., Xu, W., and Mao, Z. (2017), "Motivation for family vacations with young children: anecdotes from the Internet," Journal of Travel \& Tourism Marketing, Vol. 34, No. 8, pp. 1047-1057.

Light, D. (2009), "Performing Transylvania: Tourism, fantasy and play in a liminal place," Tourist Studies, Vol. 9, No. 3, pp. 240-258.

Masten, D. L., and Plowman, T. M. (2003), "Digital ethnography: The next wave in understanding the consumer experience," Design Management Review, Vol. 14, No. 2, pp. 7581.

McGrath, M.A., Sherry, J.F., and Levy, S.J. (1993), "Giving voice to the gift: the use of projective techniques to recover lost meanings," Journal of Consumer Psychology, Vol. 2, No. 2,171-191.

Miles, M. B., and Huberman, A. M. (1994), Qualitative Data Analysis: An Expanded Sourcebook, SAGE Publications, Thousand Oaks, CA.

Paay, J., Kjeldskov, J., Skov, M. B., \& O'Hara, K. (2013), "F-formations in cooking together: A digital ethnography using YouTube," 14th International Conference on Human-Computer Interaction (INTERACT), Sep 2013, Cape Town, South Africa.

Pace, S. (2008), "YouTube: an opportunity for consumer narrative analysis?," Qualitative Market Research: An International Journal, Vol. 11, No. 2), pp. 213-226.

Patton, M. Q. (2005), Qualitative Research, John Wiley \& Sons, Ltd., Hoboken, NJ.

Poria, Y., and Timothy, D. J. (2014), "Where are the children in tourism research?," Annals of Tourism Research, Vol. 47, pp. 93-95.

Schänzel, H. A., and Yeoman, I. (2015), "Trends in family tourism," Journal of Tourism Futures, Vol. 1, No. 2, pp.141-147.

Singh, R., and Nayak, J. K. (2014), "Peer interaction and its influence on family purchase decision: A study among Indian teenagers," Vision, Vol. 18, No. 2, pp. 81-90.

Spiggle, S. (1994), “Analysis and interpretation of qualitative data in consumer research," Journal of Consumer Research, Vol. 21, No. 3, pp.491-503.

Snelson, C. (2015), "Vlogging about school on YouTube: An exploratory study," new media \& society, Vol. 17, No. 3, pp. 321-339.

Steinberg, S. B. (2016), "Sharenting: Children's Privacy in the Age of Social Media," Emory Law Journal, Vol. 66, pp. 840-883.

Therkelsen, A. (2010), "Deciding on family holidays - role distribution and strategies in use," Journal of Travel \& Tourism Marketing, Vol. 27, No. 8, pp. 765-779. 
Therkelsen, A., and Lottrup, M. (2015), "Being together at the zoo: Zoo experiences among families with children," Leisure Studies, Vol. 34, No. 3, pp. 354-371.

Thompson, C. J. (1997), "Interpreting consumers: a hermeneutical framework for deriving marketing insights from the texts of consumers' consumption stories," Journal of Marketing Research, Vol. 34, No. 4, pp. 438-455.

Thornton, P. R., Shaw, G., and Williams, A. M. (1997), “Tourist group holiday decision-making and behaviour: The influence of children," Tourism Management, Vol. 18, No. 5, pp. 287-297.

Topinka, A. (2015), "No-fail tips for pulling off a surprise vacation," TravelingMom.com, accessed at: https://www.travelingmom.com/travel-tips/no-fail-tips-pulling-off-surprise-familyvacation/.

Wu, K. L., Holmes, K., \& Tribe, J. (2010), 'Where do you want to go today?'An analysis of family group decisions to visit museums, Journal of Marketing Management, Vol. 26, No. 7-8, 706-726. 
Table 1. Subset of Sample for Contextual Reference of the Data

\begin{tabular}{|c|c|c|c|c|c|c|}
\hline $\begin{array}{l}\text { Child(ren) } \\
\text { and Ages* }\end{array}$ & $\begin{array}{c}\text { Country } \\
\text { of } \\
\text { Origin }\end{array}$ & Destination & $\begin{array}{l}\text { Location } \\
\text { of Reveal }\end{array}$ & $\begin{array}{l}\text { Video } \\
\text { Length }\end{array}$ & $\begin{array}{l}\text { Year } \\
\text { Posted }\end{array}$ & $\begin{array}{l}\text { Description of } \\
\text { Reveal }\end{array}$ \\
\hline Madison, age 4 & USA & $\begin{array}{l}\text { Disneyland in } \\
\text { California, } \\
\text { USA }\end{array}$ & $\begin{array}{l}\text { In family } \\
\text { home }\end{array}$ & $5: 22$ & 2014 & $\begin{array}{l}\text { Madison's mother } \\
\text { and father give her } \\
\text { a bookbag filled } \\
\text { with Disney } \\
\text { themed goodies } \\
\text { and ask her to } \\
\text { guess where they } \\
\text { are going. }\end{array}$ \\
\hline $\begin{array}{l}\text { Jackson, age } 5 \\
\text { Vee, age } 5\end{array}$ & USA & $\begin{array}{l}\text { Disney World } \\
\text { in Orlando, } \\
\text { Florida, USA }\end{array}$ & $\begin{array}{l}\text { In backseat } \\
\text { of family } \\
\text { car }\end{array}$ & $2: 51$ & 2010 & $\begin{array}{l}\text { Jackson and Vee } \\
\text { are surprised with } \\
\text { a trip to Disney } \\
\text { World, which they } \\
\text { discover as they } \\
\text { see the entrance. }\end{array}$ \\
\hline $\begin{array}{l}\text { Aaron, } \sim \text { age } 5 \\
\text { Diana, age } 8\end{array}$ & England & Majorca, Spain & $\begin{array}{l}\text { In backseat } \\
\text { of family } \\
\text { car }\end{array}$ & $1: 41$ & 2017 & $\begin{array}{l}\text { Children were told } \\
\text { they were going on } \\
\text { vacation in } \\
\text { Cornwall, UK; } \\
\text { their dad gives } \\
\text { them the boarding } \\
\text { passes for Spain on } \\
\text { the way to the } \\
\text { airport. }\end{array}$ \\
\hline Jeannie, age 6 & England & $\begin{array}{l}\text { Disney World } \\
\text { in Orlando, } \\
\text { Florida, USA }\end{array}$ & $\begin{array}{l}\text { At home; at } \\
\text { airport; on } \\
\text { airplane; in } \\
\text { rental car }\end{array}$ & $16: 47$ & 2016 & $\begin{array}{l}\text { Jeannie believes } \\
\text { they are going to } \\
\text { Spain; she does not } \\
\text { discover she is in } \\
\text { Florida until } \\
\text { arriving at Disney. }\end{array}$ \\
\hline $\begin{array}{l}\text { Hannah, age } 6 \\
\text { Misha, age } 11 \\
\text { Kylie, age } 14 \\
\text { Nicole, age } 15 \\
\text { Lyssa, age } 17\end{array}$ & Australia & $\begin{array}{l}\text { Vanuatu and } \\
\text { New Caledonia } \\
\text { on an 11-day } \\
\text { cruise }\end{array}$ & $\begin{array}{l}\text { In backseat } \\
\text { of family } \\
\text { car }\end{array}$ & $2: 24$ & 2017 & $\begin{array}{l}\text { Parents told their } \\
\text { five daughters they } \\
\text { would be going to } \\
\text { Coffs Harbour for } \\
\text { the week. When } \\
\text { they pull into the } \\
\text { cruise ship } \\
\text { terminal, they give } \\
\text { the girls their } \\
\text { boarding passes. }\end{array}$ \\
\hline
\end{tabular}




\begin{tabular}{|c|c|c|c|c|c|c|}
\hline $\begin{array}{l}\text { Lauren, age } 8 \\
\text { Rex, age } 9 \\
\text { Elaine, age } 13\end{array}$ & USA & $\begin{array}{l}\text { Six Flags Over } \\
\text { Georgia, USA } \\
\text { (amusement } \\
\text { and water park) }\end{array}$ & $\begin{array}{l}\text { In backseat } \\
\text { of family } \\
\text { car }\end{array}$ & $1: 10$ & 2013 & $\begin{array}{l}\text { The three } \\
\text { children's } \\
\text { grandmother } \\
\text { makes them ride in } \\
\text { the car with towels } \\
\text { over their heads; } \\
\text { they discover the } \\
\text { surprise when they } \\
\text { remove the towels. }\end{array}$ \\
\hline $\begin{array}{l}\text { Ryan, age } 8 \\
\text { Brady, age } 10 \\
\text { May, age } 12 \\
\text { Elena, age } 15\end{array}$ & USA & Hawaii, USA & $\begin{array}{l}\text { In family } \\
\text { home }\end{array}$ & $1: 50$ & 2016 & $\begin{array}{l}\text { Parents wake } \\
\text { children up around } \\
5 \text { a.m. and ask } \\
\text { them, "What do } \\
\text { you think about } \\
\text { not going to school } \\
\text { today?... How } \\
\text { about we go to } \\
\text { Hawaii?" }\end{array}$ \\
\hline $\begin{array}{l}\text { Nick, age } 9 \\
\text { Alison, age } 14 \\
\text { Mike, age } 15\end{array}$ & USA & $\begin{array}{l}\text { Disney World } \\
\text { in Orlando, } \\
\text { Florida, USA }\end{array}$ & $\begin{array}{l}\text { In backseat } \\
\text { of family } \\
\text { car }\end{array}$ & $1: 35$ & 2016 & $\begin{array}{l}\text { Mother and father } \\
\text { told the three } \\
\text { children they were } \\
\text { going to see their } \\
\text { old house in } \\
\text { Tennessee }\end{array}$ \\
\hline Pierre, age 12 & Ireland & Spain & $\begin{array}{l}\text { In parking } \\
\text { lot of } \\
\text { airport }\end{array}$ & $2: 53$ & 2017 & $\begin{array}{l}\text { Pierre believes he } \\
\text { is dropping his } \\
\text { grandparents off at } \\
\text { the airport; his dad } \\
\text { surprises him with } \\
\text { a boarding pass } \\
\text { upon arrival. }\end{array}$ \\
\hline Ella, age 14 & Canada & $\begin{array}{l}\text { Wizarding } \\
\text { World of Harry } \\
\text { Potter in } \\
\text { Orlando, } \\
\text { Florida, USA }\end{array}$ & $\begin{array}{l}\text { In backseat } \\
\text { of family } \\
\text { car }\end{array}$ & $2: 08$ & 2011 & $\begin{array}{l}\text { For Ella's } \\
\text { birthday, her } \\
\text { parents pre- } \\
\text { recorded a 'fake' } \\
\text { radio } \\
\text { announcement to } \\
\text { play in the car. }\end{array}$ \\
\hline
\end{tabular}

* Pseudonyms are used. Exact ages are provided, when available. Where $(\sim)$ is denoted, age is estimated through two independent coders. 
Table 2. Embodied Tensions between Normative Expectations and Unanticipated Experiences in Surprise Family Vacations

\begin{tabular}{|c|c|c|c|}
\hline \multirow{2}{*}{$\begin{array}{c}\text { Performance } \\
\text { Practices in Surprise } \\
\text { Family Vacations }\end{array}$} & \multirow{2}{*}{ Description } & \multicolumn{2}{|c|}{ Embodied Tensions } \\
\hline & & NORMATIVE EXPECTATIONS & UNANTICIPATED EXPERIENCES \\
\hline \multirow[b]{2}{*}{$\begin{array}{l}\text { Executing the } \\
\text { Reveal }\end{array}$} & \multirow{2}{*}{$\begin{array}{l}\text { Executing the reveal captures } \\
\text { the rising action of the } \\
\text { performing. A tension emerges } \\
\text { based on the nature of the act: } \\
\text { scripted versus improvised. }\end{array}$} & Scripted Act & Improvised Act \\
\hline & & $\begin{array}{ll}\text { - } & \text { Planned and produced } \\
\text { - } & \text { Props are self-explanatory } \\
\text { - } & \text { Supported via technology }\end{array}$ & $\begin{array}{ll}\text { - } & \text { Ad-libbed and disordered } \\
\text { - } & \text { Props require explanation } \\
\text { - } & \text { Upended via technology }\end{array}$ \\
\hline \multirow[b]{2}{*}{$\begin{array}{l}\text { Announcing the } \\
\text { Destination }\end{array}$} & \multirow{2}{*}{$\begin{array}{l}\text { Announcing the surprise } \\
\text { destination captures the climax } \\
\text { of the performance. A tension } \\
\text { emerges based on idealized } \\
\text { perceptions of the destination: } \\
\text { absolute versus relative. }\end{array}$} & Absolute Ideal & Relative Ideal \\
\hline & & $\begin{array}{l}\text { - Stereotypical view of 'best' } \\
\text { family vacation destination } \\
\text { - Hierarchical positioning of } \\
\text { desired destinations }\end{array}$ & $\begin{array}{l}\text { - Atypical view of 'best' } \\
\text { family vacation destination } \\
\text { - Attachment to promised or } \\
\text { imagined destination }\end{array}$ \\
\hline \multirow[b]{2}{*}{$\begin{array}{l}\text { Reacting to the } \\
\text { Surprise }\end{array}$} & \multirow{2}{*}{$\begin{array}{l}\text { Reacting to the surprise } \\
\text { captures the falling action of the } \\
\text { performance. A tension } \\
\text { emerges based on the initial } \\
\text { response of the child: } \\
\text { acceptance versus rejection. }\end{array}$} & Initial Acceptance & Initial Rejection \\
\hline & & $\begin{array}{ll}\text { - } & \text { Enthusiasm and gratitude } \\
\text { - } & \text { Escape from regular routine } \\
\text { - } & \text { Free from trivial details and } \\
& \text { preparation }\end{array}$ & $\begin{array}{ll}\text { - } & \text { Skepticism and anxiety } \\
\text { - } & \text { Disruptive to regular routine } \\
\text { - } & \text { Unaddressed practical } \\
\text { concerns and desires }\end{array}$ \\
\hline
\end{tabular}

